which are directed only at individual people are not cost effective.

Some health campaigners have called for a national food and nutrition policy as the top priority for preventing and controlling cardiovascular disease in developing countriesjust as in Western ones. ${ }^{12}$ In practice, however, undernutrition remains a major public health issue in many developing countries, and it may be unrealistic to expect a policy that encourages a low fat, low salt diet to become a top priority. Instead emphasis should be given to controlling the tobacco industry. The required policy instruments are well known, and tobacco taxation seems to be a particularly powerful means of reducing consumption in developing countries. ${ }^{13}$ A few countries rely economically on growing tobacco, and the development and implementation of a national tobacco control policy, including bans on advertising and promotion, will be strenuously resisted by the international tobacco industry and other vested interests. Fortunately, considerable international experience and support are available to assist in the introduction of comprehensive tobacco control policies.

The high risk strategy focuses on individual people at high risk of disease. It can deal cost effectively only with the later stages of the diseases and will not by itself prevent the epidemic. Cost effective interventions should supplement, not replace, the essential population strategy. ${ }^{1+}$ Treatments, such as aspirin for the management of acute myocardial infarction, should be used only for people at high absolute risk. The management, either pharmacologically or nonpharmacologically, of people at low absolute risk of disease is not indicated despite the popularity of this approach in developed countries.

Prevention of cardiovascular disease can be remarkably successful, but the part played by supranational determinants, including multinational companies and trade agreements, makes international leadership essential. The problem must be high on the agenda of international agencies, especially the World Health Organisation. A strategic plan is required to build sustained international support and action; the development of epidemiological expertise in developing countries is an essential starting point.

Professor of Community Health,

ROBERT BEAGLEHOLE

Department of Community Health,

School of Medicine,

University of Auckland,

Auckland, New Zealand

World Health Organisation. World health statistics annual 1991. Geneva, WHO: 1992:25-6.

2 Hughes K. Trends in mortality from ischaemic heart disease in Singapore, 1959 to 1983. Int F Epidemiol 1986;15:44-50.

Cruz-Coke R. Cardiovascular disease in Chile. Prev Med 1985;14:541-7.

4 Feachem RGA, Kjellstrom T, Murray CJL, Over M, Phillips MA, eds. The health of adults in the developing world. London: Population and Human Resources Department, World Bank, 1991

5 Lopez AD. Causes of death in the industrialised and the developing countries: estimates for 1985 In: Jamison DT, Mosley WH, eds. Disease control priorities in developing countries. New York: Oxford University Press (in press).

6 Nissinen A, Bothig S, Granroth H, Lopez AD. Hypertension in developing countries. World Health Stat $Q 1988 ; 41: 141-54$.

7 Bovet P, Shamlaye C, Kitua JJ, Reisen WF, Paccaud F, Darioli R. High prevalence of cardiovascular risk factors in the Seychelles (Indian Ocean). Arteriosclerosis and Thrombosis 1991;11:1730-6.

8 INCLEN Multicentre Collaborative Group. Risk factors for cardiovascular disease in the developing world. A multicentre collaborative study in the international clinical epidemiology network (INCLEN). I Clin Epidemiol 1992;45:841-7.

9 Campos H, Mata L, Siles X, Vives MS, Ordovas JM, Schaefer EJ. Prevalence of cardiovascular risk factors in rural and urban Costa Rica. Circulation 1992;85:648-58.

10 Ulbricht TLV, Southgate DAT. Coronary heart disease: seven dietary factors. Lancet 1991;338: 985-92.

11 Rose G. Sick individuals and sick population. Int $f$ Epidemiol 1985;14:32-8.

12 Milio N. Nutritional policy for food-rich countries: a strategic analysis. Baltimore: Johns Hopkins University Press, 1990.

13 Chapman S, Richardson J. Tobacco excise and declining tobacco consumption: the case of Papua New Guinea. Am $\mathcal{F}$ Public Health 1990;80:537-40.

14 Pearson TA, Jamison DT, Trego-Gutierrez J. Cardiovascular disease. In: Jamison DT, Mosley WH, eds. Disease control prionities in developing countries. New York: Oxford University Press (in press)

\title{
Self monitoring of blood glucose concentrations by non-insulin dependent diabetic patients
}

\section{Of unproved value and often done badly}

Should people with non-insulin dependent diabetes mellitus monitor their blood glucose concentrations? The benefits suggested for insulin dependent patients could apply equally well to them. These benefits include more accurate information than that available from urine testing, particularly in patients with abnormal renal thresholds; information about everyday fluctuations; and encouragement for patients to become more active partners in their management.

When strips for blood glucose monitoring were introduced on to the drug tariff in Britain their use by non-insulin dependent patients was specifically excluded. In its consensus statement the American Diabetes Association sat on the fence, commenting that "although controversial, SMBG [self monitoring of blood glucose concentration] may be useful for patients not treated with insulin." ${ }^{2}$ Yet many such patients have poor glycaemic control, often because of poor compliance, and it is an attractive hypothesis that improvements might follow if they could obtain immediate and accurate feedback on the effect of eating and exercise on control.

An early study of this was encouraging - after a month's monitoring 21 of 53 patients taking oral hypoglycaemic drugs stopped their tablets completely, nine reduced their dose, six increased it, and six changed to insulin. ${ }^{3}$ Lack of a control group makes interpretation of these results difficult, but despite the financial disincentive over three quarters of patients elected to continue monitoring their blood glucose concentrations rather than go back to testing their urine.

In a randomised study Wing and colleagues added self monitoring of blood glucose concentration to a programme to control weight but found that it conferred no additional advantage in terms of weight loss or glycaemic control. ${ }^{+}$ Compliance with self monitoring, however, was excellent, and self measured blood glucose concentrations correlated well with haemoglobin $A_{1}$ concentrations, leading the authors to conclude that their patients were monitoring accurately but not using the information to alter diet or exercise. A similar problem is well recognised in some insulin dependent patients, who collect mountains of data documenting poor control but do nothing about it, ${ }^{5}$ probably because of anxiety about altering treatment without explicit medical approval.

Recent studies have not suggested any special advantages from non-insulin dependent diabetic patients monitoring their blood glucose concentrations. A retrospective American study found no differences in glycaemic control between patients who had and had not been monitoring their blood glucose concentrations. ${ }^{6}$

Other studies have found that patients randomised either to measuring their blood glucose concentrations or to testing 
their urine for glucose achieved similar improvements in glycaemic control. ${ }^{\text {i }}$

If patients are to monitor their blood glucose concentrations then careful teaching is required, particularly in older patients. A study of self monitoring published in this week's journal found that almost half the patients made substantial errors, often because of cognitive or physical impairment (p 1194). ${ }^{9}$ Visual interpretation of strips was another cause of error, and many doctors, having seen records of blood glucose concentrations that seem to be a random selection of the numbers 11,17 , or 28 , will doubt that blood glucose monitoring is more informative than urine testing. Meters may improve accuracy but may themselves be a source of error if wiping the stick or pressing the button to start the timer is required. For older patients meters that do not require either of these actions are preferable.

An important finding of Campbell and colleagues was that capillary and venous blood glucose concentrations measured by patients at home were significantly lower than concentrations measured at the clinic-a phenomenon that they call white coat hyperglycaemia (analagous to white coat hypertension) and attribute to stress. ${ }^{9}$ The authors suggest that clinic visits should be made as stress free as possible and that other ways of rapidly assessing diabetic control, such as glycosylated haemoglobin, should be available. In fact, because fasting plasma glucose correlates closely with glycosylated haemoglobin ${ }^{1011}$ (and hence control) the cheapest and most effective way of monitoring glycaemic control is for practice nurses to measure fasting blood concentrations every three months. ${ }^{12}$

The two problems with this strategy are that patients may not actually be fasting and, more importantly, practice nurses may not have been trained to measure blood glucose concentrations accurately enough. Studies of the accuracy of hospital nurses suggest that auditing the performance of practice nurses would be worthwhile. For example, in a Canadian teaching hospital $40 \%$ of readings by nurses deviated by more than $20 \%$ from laboratory results. ${ }^{13}$ In a study in four hospitals Lawrence et al found that readings were accurate only in the hospital where nurses had to prove their technique and accuracy each year before being allowed to measure blood glucose concentrations. ${ }^{14}$ Some British hospitals have introduced quality assurance schemes for such measurements; they should be mandatory in general practice. Diabetic patients will inevitably produce dud results if their teachers are incompetent.

Professor of Clinical Diabetes,

ROBERT TATTERSALL

University Hospital,

Nottingham NG7 2UH

1 Tattersall RB. Home blood glucose monitoring. Diabetologia 1979;16:71-4

2 American Diabetes Association. Consensus statement: self-monitoring of blood glucose. Diabetes Care 1987;10:95-9.

3 Cohen M, Zimmet P. Self-monitoring of blood glucose levels in non-insulin dependent diabetes melitus. Med F Aust 1983;2:377-80.

4 Wings RR, Epstein LH, Norwalk MP, Scott N, Noeska R, Haggs S. Does self-monitoring of blood glucose levels improve dietary compliance for obese patients with type 2 diabetes? Am $\mathcal{f}$ Med 1986;81:830-5.

Cox R, Beaven DW, Helm AM. Home monitoring of blood glucose: a retrospective assessment in 38 insulin requiring diabetics. NZ Med f 1980;92:193-7.

6 Newman WP, Laqua D, Engelbrecht D. Impact of glucose self-monitoring on glycohemoglobin values in a veteran population. Arch Intern Med 1990;150:107-10.

7 Allen BT, De Long ER, Feussner JR. Impact of glucose self-monitoring on non-insulin treated patients with type II diabetes mellitus. Randomised controlled trial comparing blood and urine patients with type II diabetes mellitus.
testing. Diabetes Care 1990;13:1044-50.

8 Forbonne A, Billaut B, Acosta $M$, Percheron C, Varenne P, Besse A, et al. Is glucose selfmonitoring beneficial in non-insulin treated diabetic patients? Results of a randomised monitoring beneficial in non-insulin treated

9 Campbell LV, Ashwell S, Borkman M, Chisholm DJ. White-coat hyperglycaemia? The disparity between diabetes clinic and home blood glucose levels. BMF 1992;305:1194-6.

10 Pecoraro RE, Koepsell TD, Chen MS, Lipsky BA, Belcher DW, Inui TS. Comparative clinical reliability of fasting plasma glucose and glycosylated hemoglobin in non-insulin dependent diabetes. Diabetes Care 1986;9:70-5

11 Paisey RB, Bradshaw P, Harog M. Home blood glucose concentrations in maturity onset diabetes. BMF 1980;i:596-8.

12 Howe-Davis S, Simpson R, Turner R. Control of maturity-onset diabetes by monitoring fasting blood glucose and body weight. Diabetes Care 1980;3:607-10.

13 Ting C, Nanii AA. Evaluation of the quality of bedside monitoring of the blood glucose level in a teaching hospital. Can Med Assoc $\mathcal{F}$ 1988;138:23-6.

14 Lawrence PA, Dowe MC, Perry EK, Strong S, Samsa GP. Accuracy of nurses in performing capillary blood glucose monitoring. Diabetes Care 1989;12:298-301

\section{Pregnancy and ionising radiation}

\section{Most occupational exposure adds little to background levels}

About a quarter of a million people are occupationally exposed to ionising radiation in Britain. ${ }^{1} \mathrm{~A}$ fifth of these are women, nearly all working in the health services or as aircrew. What advice should they be given about pregnancy?

Large doses of radiation are harmful, yet we cannot accurately determine the risks of small doses because any small increase in cancer or inherited disease is masked by the natural variation in these conditions. The effects of small doses of ionising radiation are probably not analogous to small insults of heat, cold, trauma, or poison, which have thresholds below which no injury occurs. Ionising radiation deposits its energy in very small, subatomic sized volumes. At a point of ionisation the energy deposited per unit mass is similar to that at the centre of an atomic explosion. It causes injury to chromosomes, and this injury occurs at very low doses. $^{2}$ Trends of increasing rates of cancer are seen in workers in the atomic power industry exposed at low dose rates and to low doses. ${ }^{3}$

The harm done by ionising radiation depends on two factors: the effect per unit dose and the dose received. With regard to induction of cancer, for exposures in utero the International Commission on Radiological Protection assumes for a lifetime a nominal fatality probability coefficient "at most a few times that for the population as a whole." figure is $5 \% / \mathrm{Sv}$. Non-fatal cancers also occur. The National Radiological Protection Board suggests that in childhood the excess cancer rate after fetal exposure is $6 \% / \mathrm{Sv}$, half of the cases being expected to be fatal. ${ }^{5}$ The excess risk of fatal cancer over a lifetime after a fetal exposure is estimated at around 1 in $10000 / \mathrm{mSv}$.

The genetic risk in the female varies with the degree of development in the oocyte. In the human the first reduction division (meiosis) of the oocyte begins in the fetus but is arrested in the diplotene phase after DNA replication has occurred. The oocyte stays in this arrested state until some weeks before ovulation when the first meiotic division is completed. The second reduction division then starts and is completed after fertilisation. Animal experiments suggest, and observations in women confirm, that during the long resting diplotene phase, lasting through childhood and early adult life, the oocytes are resistant to radiation induced mutations and translocations.

In contrast, the oocytes in multilayered and Graafian follicles are more sensitive to genetic injury, particularly between metaphase I and metaphase II - the period from six or seven weeks before ovulation. The beginning of this sensitive period coincides with the formation of the zona pellucida and a change in the nuclear morphology of the 